International Journal of Pure and Applied Mathematics

Volume 111 No. 1 2016, 121-126

ISSN: 1311-8080 (printed version); ISSN: 1314-3395 (on-line version)

url: http://www.ijpam.eu

doi: 10.12732/ijpam.v111i1.11

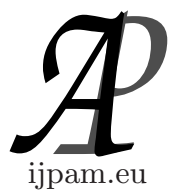

\title{
LYAPUNOV STABILITY ANALYSIS TO SET UP \\ A SATURATING PI CONTROLLER WITH ANTI-WINDUP FOR A MASS FLOW SYSTEM
}

\author{
Paolo Mercorelli \\ Institute of Product and Process Innovation \\ Leuphana University of Lueneburg \\ Volgershall 1, D-21339 Lueneburg, GERMANY
}

\begin{abstract}
This paper deals with sufficient conditions for the asymptotical stability of a mass flow controlled system. Because of the presence of a saturation an anti-windup control structure is considered to manage saturation effects. In order to analyse the stability and the dynamic performance of the controlled system a Lyapunov approach is proposed. Through this approach, conditions on the three parameters which characterise the controller (PI and anti-windup controller) are found which guarantee the asymptotical stability of the controlled system.
\end{abstract}

AMS Subject Classification: 49K15, 37N35, 34K35

Key Words: problems involving ordinary differential equations, dynamical systems in control, control problems

\section{Introduction and Motivation}

PID-type controllers are widely used in industrial applications and the number

Received: $\quad$ October 27, 2016

Revised: $\quad$ November 26, 2016

Published: $\quad$ December 6, 2016 (c) 2016 Academic Publications, Ltd. url: www.acadpubl.eu 
of them equals $90 \%$ of all industrial controllers [1]. Their qualities, such as: simplicity of the control law and the few tuning parameters allow them to be the most used controllers. Many engineers mostly use trial and error method for the tuning process, because it is still very difficult to tune the parameters for a PID controller. The problem to choose these parameters is a difficult one if the system which should be controlled is a nonlinear one. The wide usage of the PI controllers in industrial applications can be explained by the fact that they have a simple structure. Moreover, in the last years advanced PID controllers were developed to control complex and nonlinear systems. In [2] and in [3] $\mathrm{PD}$ regulators are proposed to control an electromagnetic valve actuator beside Kalman filters. Saturations can be avoided by using the proposed PI controller with an anti-windup scheme. When saturation happens, the feedback loop is effectively broken and if a controller with an integrator is used, the error will continue to be integrated. The value at the output of the controller can become very large and it often degrades the closed-loop performance in the form of large overshoot, long settling time and sometimes even instability. It can be better observed after comparing it with the expected linear performance for the systems. The phenomenon described is called windup. The windup phenomenon has attracted interest in academic and in industrial community already at the end of the eighties. The most modern anti-windup techniques, in particular for actuator applications, are described in [4] and [5]. This contribution aims to show sufficient conditions for parameters of a PI controller including an antiwindup scheme using Lyapunov approach for a mass flow system and represents a mathematical extension of the application results shown in [6] and in [7]. The paper is organised in just a section which is dedicated to the mass flow model and the PI controller with the anti-saturating structure (anti-windup). The conclusion closes the work. 


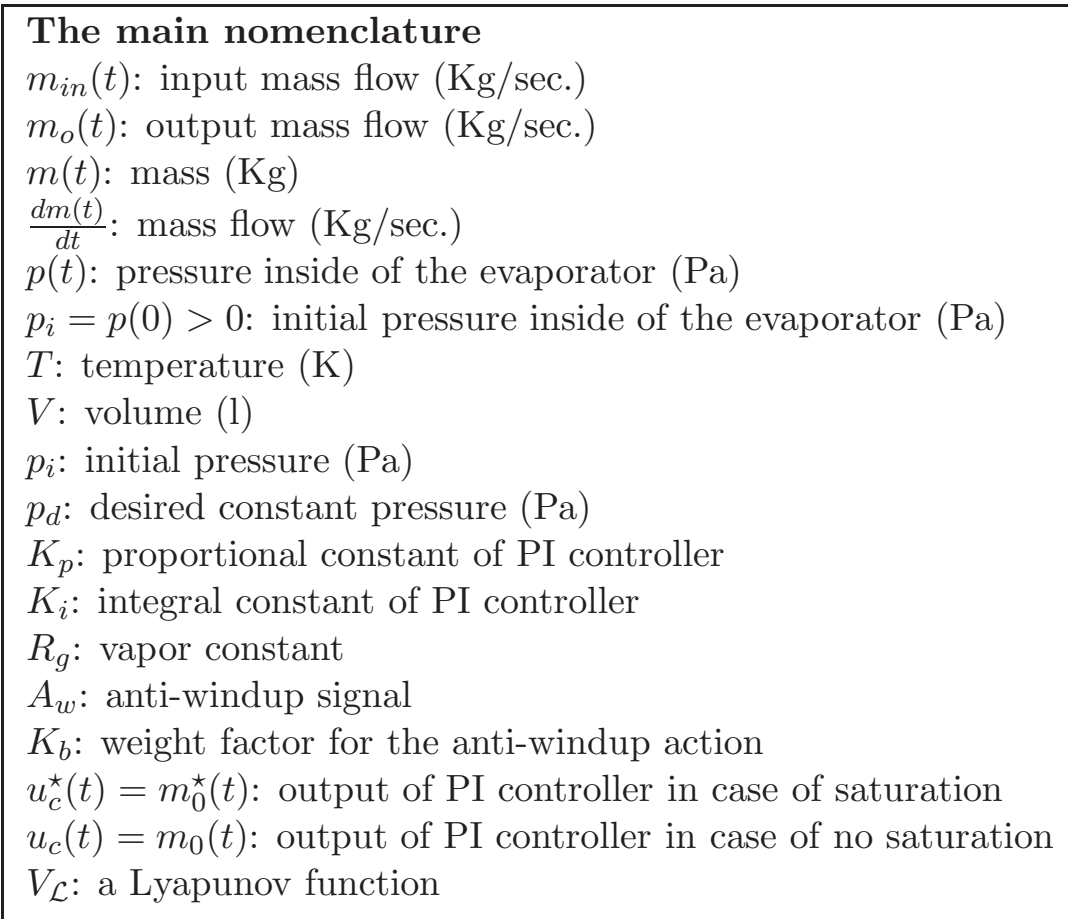

\section{The Flow Mass Model with PI Controller and Anti-Windup}

The dynamical model of the system consists of the mass flow equation and the ideal gas equation and it is represented in (1) and (2). The considered model represents a viable approach for many heating systems and it is widely used in many technical fields. If limited or saturating input $m_{0}(t)$ is considered, it can be difficult to control the system because the system to be controlled becomes a nonlinear one. Nevertheless, nonlinear elements such as input limits or saturations are always present in real applications. In this sense, it is worthwhile to analyse these cases. The following two dynamical expressions represent a possible mathematical model of a mass flow system:

$$
\begin{aligned}
\frac{d m(t)}{d t} & =m_{i}(t)-m_{o}(t), \\
\frac{d p(t)}{d t} & =\frac{d m(t)}{d t} \frac{R_{g} T}{V}
\end{aligned}
$$


in which $m_{i}(t)$ is a stepwise positive constant function.

Considering the following nonlinear PI controller for the system described above:

$$
u_{c}(t)=m_{o}(t)=K_{p}\left(p_{d}-p(t)\right)+K_{i} \int_{0}^{t}\left(p_{d}-p(\tau)\right) d \tau+A_{w}(t),
$$

with $A_{w}(t)$ which is the anti-windup signal with:

$$
A_{w}(t)=K_{b}\left(u_{c}^{*}(t)-K_{p}\left(p_{d}-p(t)\right)-K_{i} \int_{0}^{t}\left(p_{d}-p(\tau)\right) d \tau\right),
$$

with Sat out the constant of the saturating level of the compressor which is indicated and $K_{b}$ which is a constant to be set.

$$
u_{c}^{*}(t)=\left\{\begin{array}{clc}
u_{c}(t) & \text { if } & u_{c}(t)<\text { Sat }_{\text {out }} \\
\text { Sat }_{\text {out }} & \text { if } & u_{c}(t) \geq \text { Sat }_{\text {out }} \\
0 & \text { if } & u_{c}(t) \leq 0 .
\end{array}\right.
$$

Theorem 1. Let consider the system described by (1), (2) and (3), if

$$
\frac{d m_{0}(t)}{d t}>0
$$

and the three constant parameters $K_{p}, K_{i}$ and $K_{b}$ of the controller defined by (3) are such that $K_{p}<0, K_{i}<0$ and $-1<K_{b}<1$, then the controlled system results to be asymptotically stable around the desired constant pressure $p_{d}$.

Proof. From the regulator defined by (3) and (4) in case of saturation, the following expression is obtained:

$$
\begin{aligned}
u_{c}(t)=m_{o}(t)=K_{p}\left(p_{d}-p(t)\right)+K_{i} \int_{0}^{t}\left(p_{d}-p(\tau)\right) d \tau \\
+K_{b}\left(\text { Sat }_{\text {out }}-K_{p}\left(p_{d}-p(t)\right)-K_{i} \int_{0}^{t}\left(p_{d}-p(\tau)\right) d \tau\right)
\end{aligned}
$$

and thus

$$
m_{o}(t)=\left[1-K_{b}\right]\left(K_{p}\left(p_{d}-p(t)\right)+K_{i} \int_{0}^{t}\left(p_{d}-p(\tau)\right) d \tau\right)+K_{b} \text { Sat }_{\text {out }} .
$$

Differentiating expression (8) it follows:

$$
\frac{d m_{o}(t)}{d t}=\left[1-K_{b}\right]\left(-K_{p} \frac{d p(t)}{d t}+K_{i}\left(p_{d}-p(t)\right)\right) .
$$


From (6) and from $-1<K_{b}<1$ (hypothesis of Theorem 1), it follows that:

$$
-K_{p} \frac{d p(t)}{d t}+K_{i}\left(p_{d}-p(t)\right)>0,
$$

which is equivalent to prove that

$$
K_{p} \frac{d p(t)}{d t}+K_{i} p(t)<K_{i} p_{d}
$$

Considering the solution of

$$
K_{p} \frac{d p(t)}{d t}+K_{i} p(t)=0
$$

then it must be

$$
p(t)=p_{i} e^{-\frac{K_{i}}{K_{p}} t}<\frac{p_{d}}{K_{p}} K_{i},
$$

where $p_{i}=p(0)$ with $p(0)>0$. From (11) and (12) the following condition on $K_{i}$ and $K_{p}$ is obtained:

$$
K_{i}>\frac{p(0)}{p_{d}} K_{p}
$$

Taking into consideration (12) and that $K_{i}<0$ as well $K_{p}<0$, it follows that:

$$
\frac{d p(t)}{d t}<0,
$$

and thus from (2), being $\frac{V}{T R_{g}}>0$, it follows:

$$
\frac{d m(t)}{d t}=\frac{V}{T R_{g}} \frac{d p(t)}{d t}<0
$$

In order to show the asymptotical stability of the controlled system, the following Lyapunov function is chosen:

$$
V_{\mathcal{L}}(p(t))=\frac{1}{2}\left(p_{d}-p(t)\right)^{2}+K_{i} \int_{0}^{t}\left(p_{d}-p(t)\right)^{2} d \tau,
$$

in which the state of the system is considered together with the state of the integral action of the controller. Differentiating (16), it follows:

$$
\frac{d V_{\mathcal{L}}(p(t))}{d t}=-\left(p_{d}-p(t)\right)\left(\frac{d p(t)}{d t}-K_{i}\left(p_{d}-p(t)\right)\right)
$$


and considering that

$$
\frac{d p(t)}{d t}=\frac{d m(t)}{d t} \frac{R_{g} T}{V}
$$

then it follows that:

$$
\frac{d V_{\mathcal{L}}(p(t))}{d t}=-\left(p_{d}-p(t)\right)\left(\frac{d m(t)}{d t} \frac{R_{g} T}{V}-K_{i}\left(p_{d}-p(t)\right)\right) .
$$

From (9), being

$$
\left(p_{d}-p(t)\right)=\frac{d m_{o}(t)}{d t} \frac{1}{\left[1-K_{b}\right] K_{i}}+\frac{d p(t)}{d t} \frac{K_{p}}{K_{i}}
$$

it follows that:

$$
\begin{aligned}
\frac{d V_{\mathcal{L}}(p(t))}{d t}=-\left(\frac{d p(t)}{d t} \frac{K_{p}}{K_{i}}\right. & \left.+\frac{d m_{o}(t)}{d t} \frac{1}{\left[1-K_{b}\right] K_{i}}\right) \\
& \left(\frac{d m(t)}{d t} \frac{R_{g} T}{V}-\frac{d m_{o}(t)}{d t} \frac{1}{\left[1-K_{b}\right]}-\frac{d p(t)}{d t} K_{p}\right) .
\end{aligned}
$$

From the fact that $\frac{R_{g} T}{V}>0, \frac{d m_{o}(t)}{d t}>0$ and according to (14) and (15) $\frac{d p(t)}{d t}<0$ and $\frac{d m(t)}{d t}<0$ respectively, then, if $K_{p}<0, K_{i}<0$ and $-1<K_{b}<1$ as stated in Theorem 1, the following sufficient Lyapunov condition on the asymptotical stability is guaranteed:

$$
\frac{d V_{\mathcal{L}}(p(t))}{d t}<0
$$

\section{Conclusions}

Sufficient asymptotical stability conditions to set parameters of a PI controller to be applied in a mass flow system are found. Because of the presence of a saturation, the system to be controlled is a nonlinear one and in order to analyse the stability and the dynamic performance of the controlled system a Lyapunov approach is proposed.

\section{References}

[1] M. Lelic and Z. Gajic, A reference guide to PID controllers in the nineties, In Proceedings of PID '00: IFAC Workshop on Digital Control, 73-82, Terrassa, Spain, 2000. 
[2] P. Mercorelli, A two-stage augmented extended Kalman filter as an observer for sensorless valve control in camless internal combustion engines, IEEE Transactions on Industrial Electronics, 59, No. 11 (2012), 4236-4247.

[3] P. Mercorelli, A hysteresis hybrid extended Kalman filter as an observer for sensorless valve control in camless internal combustion engines, IEEE Transactions on Industry Applications, 48, No. 6 (2012), 1940-1949.

[4] L. Zaccarian and A.R. Till, Moderne Anti-Windup Synthesis: Control Augmentation for Actuator Saturaion, Princeton University Press, Princeton, New Jersey, 2011.

[5] S. Tarbouriech, G. Garcia, J.M.G. da Silva Jr., and I. Queinnec, Stability and Stabilisation of Linear Systems with Saturating Actuators, Springer-Verlag London, 2011.

[6] P. Mercorelli, R. Halbe, and J. Goes, A Lyapunov based PI controller with an antiwindup scheme for a purification process of potable water, In: Proceedings of the IEEE International Conference on Control, Decision and Information Technologies, CoDIT 2014, pages 578-583, Metz, 2014.

[7] Paolo Mercorelli, An optimal and stabilising PI controller with an anti-windup scheme for a purification process of potable water, IFAC-PapersOnLine, 48, No. 25 (2015), 259-264. 
